Original data for a paper:

\title{
RESPONSES OF A NATIVE PLANT SPECIES FROM INVADED AND UNINVADED AREAS TO ALLELOPATHIC EFFECTS OF AN INVADER
}

Anne Lyytinen \& Leena Lindström, University of Jyväskylä, Centre of Excellence in Biological Interactions Research, Department of Biological and Environmental Science, P.O. Box 35, FI40014 University of Jyväskylä, Finland

anne.m.lyytinen@jyu.fi

leena.m.lindstrom@jyu.fi

Published in Ecology and Evolution, DOI: 10.1002/ece3.5195

Copyright of the dataset published in JYX belongs to authors together with JYU.

\begin{abstract}
Invaders exert new selection pressures on the resident species e.g. through competition for resources or by using novel weapons. It has been shown that novel weapons aid invasion but it is unclear whether native species co-occurring with invaders have adapted to tolerate these novel weapons. Those resident species which are able to adapt to new selective agents can co-occur with an invader while others face a risk of local extinction. We ran a factorial common garden experiment to study whether a native plant species, Anthriscus sylvestris, has been able to evolve a greater tolerance to the allelochemicals exerted by the invader, Lupinus polyphyllus. Lupinus polyphyllus produces allelochemicals which potentially act as a novel, strong selective agent on A. sylvestris. We grew A. sylvestris seedlings collected from uninvaded (naïve) and invaded (experienced) sites growing alone and in competition with $L$. polyphyllus in pots filled with soil with and without activated carbon. Because activated carbon absorbs allelochemicals, its addition should improve especially naïve A. sylvestris performance in the presence of the invader. To distinguish the allelochemicals absorption and fertilizing effects of activated carbon, we grew plants also in a mixture of soil and fertilizer. A common garden experiment indicated that the performances of naïve and experienced $A$. sylvestris seedlings did not differ when grown with L. polyphyllus. The addition of activated carbon, which reduces interference by allelochemicals, did not induce differences in their performances although it had a positive effect on the aboveground biomass of $A$. sylvestris. Together these results suggest that naïve and experienced $A$. sylvestris plants tolerated equally the invader L. polyphyllus and thus the tolerance has not occurred over the course of invasion.
\end{abstract}

\section{MATERIALS AND METHODS}

Seedlings of cow parsleys, Anthriscus sylvestris, were collected from three sites invaded (hereafter experienced) by a garden lupine, Lupinus polyphyllus, and from three uninvaded sites (hereafter naïve) in Central Finland (Jyväskylä, $62^{\circ} \mathrm{N}, 25^{\circ} \mathrm{E}$ ). Anthriscus sylvestris was planted together with L. polyphyllus in $3 \mathrm{~L}$ pots (diameter: $16 \mathrm{~cm}$, tall: $12 \mathrm{~cm}$ ) filled with a $2.5 \mathrm{~L}$ of 1:1 mixture of potting soil (Kekkilä Oy, viljelyseos) and sand. Both $A$. sylvestris and $L$. polyphyllus were also planted alone. Plants grown alone and in pairs were assigned into the three soil treatments: control, activated carbon and fertilizer treatment (Table 1). Activated carbon ( $20 \mathrm{ml} \mathrm{L-1}$ of soil, Merck KGaA) was mixed with the substrate to ameliorate the allelopathic effects of $L$. polyphyllus. As a control for the activated carbon treatment we added 
Table 1. The number of plants in each treatment at the beginning of the first and second growing season. In the second year, only those plant pairs were included where both were alive after the first winter. Plants were collected from uninvaded (naïve) and invaded (experienced) sites. A. sylvestris plants, which were grown alone or in competition with the invader L. polyphyllus, were allocated to soil treatments: control, activated carbon and fertilizer.

\begin{tabular}{|c|c|c|c|c|c|}
\hline \multirow[b]{2}{*}{ Species } & \multirow[b]{2}{*}{$\begin{array}{l}\text { Invasion } \\
\text { history }\end{array}$} & \multirow[b]{2}{*}{ Competition treatment } & \multicolumn{3}{|c|}{$\begin{array}{c}\text { Soil treatment } \\
2013 / 2014\end{array}$} \\
\hline & & & Control & $A C$ & Fertilizer \\
\hline \multirow[t]{4}{*}{ A. sylvestris } & Naïve & Alone & $17 / 11$ & $17 / 13$ & $17 / 16$ \\
\hline & Experienced & Alone & $16 / 9$ & $16 / 13$ & $15 / 15$ \\
\hline & Naïve & Competition & $13 / 6$ & $13 / 5$ & $13 / 3$ \\
\hline & Experienced & Competition & $15 / 6$ & $16 / 2$ & $15 / 3$ \\
\hline
\end{tabular}

fertilizer (0.4 g per pot, Kekkilä, puutarhalannoite, NPK 9-4-13) to another set of pots. This allowed us to distinguish the absorption of allelochemicals and fertilizing effects of activated carbon (Weißhuhn \& Prati, 2009). Pots were placed randomly in a common garden at the University of Jyväskylä. The height of the stem was measured every second week until the growth was levelled off. After each measurement the order of pots were again randomized. After 14 weeks, the stem was cut at the height of $3 \mathrm{~cm}$ from ground level, dried at $48^{\circ} \mathrm{C}$ for 7 days and weighed.

For overwintering, pots were dug into the soil so that the pot rim was at the soil level. In the following spring, pots were dug up and placed in a common garden. Only those pairs where both plants were alive were included in the experiment (survival of the pair= alive). Similarly as in the first growing season, the height of the stem was measured every second week until the growth was levelled off when the stems and roots were harvested. After drying at $48^{\circ} \mathrm{C}$, the stems and roots were weighed. In total, the experiment lasted 448 days (two growing seasons).

\section{Data analysis}

We performed separate tests for competition treatments (grown alone, grown together with L. polyphyllus). To test whether plant height growth pattern of A. sylvestris differs with the invasion history or soil treatment in the first growing season, we performed a repeated 2-way ANCOVA with the height measurements as different factor levels and the invasion history (naïve, experienced) and soil treatment (control, activated carbon, fertilizer) as fixed factors and a root length of a seedling as a covariate. For the data from the second growing season, the model included also the initial shoot height of the seeding as a covariate. To test which of the factors affect the final shoot and root dry weight, and root-shoot ratio, we performed separate Generalized Linear Models where the invasion history and soil treatment were fixed factors, and a root and shoot length of a seedling were covariates. The pairwise comparisons were tested with LSD. Survival from the beginning of the experiment to the following spring was analysed with Binary Logistic regression. All analysis were performed with SPSS Statistics 24.

\section{Data description:}

Data file includes all the experimental information (invasion history of the plants, soil treatment and competition treatment), the survival (different stages) of the plants, the background information as the root_seedling (in $\mathrm{cm}$ ) and shoot_seedling $(\mathrm{cm})$, and the individual growth measurements (1-8 first season and 1-7 second season, measurement in $\mathrm{cm}$ ), mass measurements in grams (shootmass_2015, shootmass_2016, rootmass_2016) and 
finally a root_to shoot ratio. Finally there is the lifetime in days. Note that the shoot_seedling is also the measurement 1 at the first season.

ID: individual ID

Species: A. sylvestris

Invasion history: naïve, experienced

Soil_Treatment: control, Activated carbon, Fertilizer

Competition_treatment: Alone, Competition

Surivival_2015: alive, dead

Wintersurvival

Survival_spring_2016

Survival_2016

Survival_at_the end of the experiment

Faith of the pair: alive, dead

Shoot seedling/Measurement_1_2015,_cm

Root_seedling

Measurement_2_cm

Measurement_3_cm

Measurement_4_cm

Measurement_5_cm

Measurement_6_cm

Measurement_7_cm

Measurement_8_cm

Shoot_mass_2015_g

Measurement_1_2016_cm

Measurement_2_2016_cm

Measurement_3_2016_cm

Measurement_4_2016_cm

Measurement_5_2016_cm

Measurement_6_2016_cm

Measurement_7_2016_cm

Shootmass_2016_g

Rootmass_2016_g

Root_to_shoot_ratio

Lifetime 